\title{
Interfaces do PIBID na formação inicial e na práxis pedagógica num trabalho colaborativo para a construção da identidade profissional
}

\author{
Interfaces of PIBID in initial formation and pedagogical praxis in a collaborative work for the \\ construction of professional identity
}

Interfaces de PIBID en la formación inicial y la praxis pedagógica en un trabajo colaborativo para la construcción de la identidad profesional Universidade Federal do Paraná, Brasil E-mail: yanina.sammarco@gmail.com

Kaique Henrique Peixoto ORCID: https://orcid.org/0000-0002-4051-6525 Universidade Federal do Paraná, Brasil

E-mail: peixoto_kaique945@escola.pr.gov.br

Paula Barroso Litaiff

ORCID: https://orcid.org/0000-0001-9350-6323 Universidade Federal do Paraná, Brasil E-mail: litaiff_paula @escola.pr.gov.br

Leticia Ferreira Jessen

ORCID: https://orcid.org/0000-0001-8698-444X Universidade Federal do Paraná, Brasil E-mail: jessen_leticia@escola.pr.gov.br

Pedro Augusto Ramos Pedroso

ORCID: https://orcid.org/0000-0002-5656-6623 Universidade Federal do Paraná, Brasil

E-mail: pedroso_pedro910@escola.pr.gov.br

Breno Gonçalves da Silva

ORCID:https://orcid.org/0000-0003-0524-3821 Universidade Federal do Paraná, Brasil E-mail: silva_breno@escola.pr.gov.br

Jessica Costa

ORCID: https://orcid.org/0000-0002-6298-1567 Universidade Federal do Paraná, Brasil E-mail: costa_jessica@escola.pr.gov.br

Luana Aparecida da Silva

ORCID:https://orcid.org/0000-0001-6034-0830 Universidade Federal do Paraná, Brasil E-mail: silva_luana @escola.pr.gov.br

Liz Dall Agnol

ORCID: https://orcid.org/0000-0003-3175-9936 Universidade Federal do Paraná, Brasil

E-mail: agnol_liz@escola.pr.gov.br

Guilherme Cesar Navas de Araújo

ORCID: https://orcid.org/0000-0002-2664-0853 Universidade Federal do Paraná, Brasil

E-mail: araujo_guilherme@escola.pr.gov.br José Inácio Junior

ORCID: https://orcid.org/0000-0003-4938-8635 Universidade Federal do Paraná, Brasil E-mail: junior_jose@escola.pr.gov.br

\section{Resumo}

Este artigo expõe os resultados de um estudo que analisou as contribuições do Programa Institucional de Bolsas de Iniciação à Docência - PIBID, na formação inicial dos bolsistas de Licenciatura em Ciências Biológicas da 
Universidade Federal do Paraná no Colégio Estadual Newton Ferreira da Costa, na cidade de Curitiba-PR, onde as atividades foram desenvolvidas de forma remota no curso de ano letivo 2020/2021 devido ao processo de virtualização de emergência devido o avanço da pandemia da Covid-19. Metodologicamente trata-se de uma pesquisa exploratória de abordagem qualitativa e de natureza descritiva. Nos resultados, observou-se que o PIBID é uma realidade essencial e cada vez mais necessária ao nosso sistema educacional e deve ser ampliado para atingir mais acadêmicos de licenciatura, visto que este aproxima a teoria e a prática a partir da práxis pedagógica no processo de socialização profissional no trabalho colaborativo para contribuir com a melhoria da qualidade do ensino e a ressignificação do papel do professor na sociedade.

Palavras-chave: Pandemia Covid-19; Trabalho colaborativo; Socialização escolar; PIBID; Formação docente.

\begin{abstract}
This article exposes the results of a study that analysed the contributions of the Institutional Programme of Scholarships for Initiation to Teaching - PIBID, in the initial training of the fellows of Degree in Biological Sciences of the Federal University of Paraná in the State College Newton Ferreira da Costa, in the city of Curitiba-PR, where the activities were developed remotely in the course of school year 2020/2021 due to the process of emergency virtualisation due to the advancement of the Covid-19 pandemic. Methodologically, this is an exploratory research of qualitative approach and descriptive nature. In the results, it was observed that the PIBID is an essential and increasingly necessary reality for our educational system and should be expanded to reach more undergraduate students, since it brings theory and practice together from the pedagogical praxis in the process of professional socialization in collaborative work to contribute to the improvement of the quality of education and the resignification of the teacher's role in society.
\end{abstract}

Keywords: Pandemic Covid-19; Collaborative work; School socialization; PIBID; Teacher training.

\title{
Resumen
}

Este artículo expone los resultados de un estudio que analiza las contribuciones del Programa Institucional de Bolsas de Iniciación a la Docencia - PIBID, en la formación inicial de los bolsistas de Licenciatura en Ciencias Biológicas de la Universidad Federal de Paraná en el Colegio Estadual Newton Ferreira da Costa, en la ciudad de Curitiba-PR, donde las actividades se desarrollaron de forma remota en el curso de año escolar 2020/2021 debido al proceso de virtualización de la emergencia por el avance de la pandemia de Covid-19. Metodológicamente se trata de una investigación exploratoria de enfoque cualitativo y de naturaleza descriptiva. En los resultados, se observa que el PIBID es una realidad esencial y cada vez más necesaria en nuestro sistema educativo y debe ser ampliado para conseguir más académicos de licenciatura, ya que se aproxima a la teoría y a la práctica a partir de la práctica pedagógica en el proceso de socialización profesional en el trabajo colaborativo para contribuir a la mejora de la calidad de la enseñanza y a la resignificación del papel del profesor en la sociedad.

Palabras clave: Pandemia Covid-19; Trabajo colaborativo; Socialización escolar; PIBID; Formación del profesorado.

\section{Introdução}

Um dos principais indicadores de uma boa qualidade no processo de ensino e aprendizagem nas escolas refere-se à formação inicial dos professores. Contudo, Souza (2020) e Gatti (2014) aponta que a formação tem sido insuficiente já que os(as) professores(as) não se sentem preparados para atuar e lidar com os desafios diários do contexto escolar; isso porque, de um modo geral, as disciplinas ofertadas na sua formação são dissociadas da prática, causando um empobrecimento quanto à inserção do licenciando na escola.

Nesse sentido a presente pesquisa tem como objetivo analisar as contribuições do Programa Institucional de Bolsas de Iniciação à Docência - PIBID, na formação inicial dos bolsistas de Licenciatura em Biologia no Colégio Estadual Newton Ferreira da Costa, na cidade de Curitiba-PR, onde as atividades foram desenvolvidas no curso de ano letivo $2020 / 2021$. Ocorreu num contexto atípico com o avanço da pandemia da Covid-19, doença infecciosa causada pelo novo coronavírus (SARS-CoV-2), na qual o ensino presencial foi adaptado para "o ensino remoto num processo de virtualização de emergência" (Marques \& Fraguas, 2020; Marques, Fraguas \& Torales, 2021).

As mudanças que ocorreram nesse processo de virtualização de emergência na educação frente ao atual contexto da pandemia causada pelo novo coronavírus, levaram o Estado e as Universidades a adotarem metodologias alternativas, até então, não adotadas em seus ambientes de ensino. Dessa forma, "foi preciso viabilizar o desenvolvimento de atividades 
síncronas e assíncronas com o uso ferramentas que se aproximassem as práticas do ensino presencial a uma nova realidade, mediada pelo uso de tecnologias" (Marques, Fraguas \& Torales, 2021, p. 2).

Diante desse contexto, o Programa Institucional de Bolsa de Iniciação à Docência - PIBID também se adaptou ao novo formato de aproximação, integração e exercício da docência diante dos desafios contemporâneos em tempos de pandemia. Sabendo que um dos objetivos do PIBID é contribuir para a articulação entre teoria e prática necessárias à formação dos/das docentes, acredita-se que o PIBID mesmo diante dos paradigmas contemporâneos na circunstancia pandemia da Covid-19, cumpre com o objeto de corrigir as deficiências na articulação entre teoria e prática e avançar no que se refere à educação e à formação docente de qualidade.

Para contextualizar essa pesquisa, é importante dizer que o Programa Institucional de Bolsa de Iniciação à Docência PIBID foi instituído por Portaria Normativa do Ministério de Educação (MEC) de número 38, em 12 de dezembro de 2007 e implementado pela Coordenação de Aperfeiçoamento de Pessoal em Nível Superior - (CAPES) e pelo Fundo Nacional de Desenvolvimento da Educação (FNDE) tendo como uma de suas finalidades incentivar estudantes das licenciaturas das Universidades e Instituições Federais de Educação Superior (IFES) na sua "inserção no cotidiano das escolas públicas de educação básica, contribuindo para o aperfeiçoamento da formação de docentes em nível superior” (Brasil, 2019, p. 1).

Em 2019, com a criação do programa Residência Pedagógica, a CAPES reformulou o PIBID, mantendo de forma geral seus princípios e objetivos, mas restringindo a participação aos/às discentes que cursam a primeira metade do curso e a duração passou de vinte e quatro para dezoito meses.

De acordo com o Art. $4^{\circ}$ da Portaria No 259 da CAPES o PIBID como Política Pública educacional apresenta como objetivos $^{1:}$ : ‘) Incentivar a formação de docentes em nível superior para a educação básica; b) Contribuir para a valorização do magistério; c) Elevar a qualidade da formação inicial de professores nos cursos de licenciatura, promovendo a integração entre educação superior e educação básica; d) Inserir os licenciados no cotidiano de escolas da rede pública de educação, proporcionando-lhes oportunidades de criação e participação em experiências metodológicas, tecnológicas e práticas docentes de caráter inovador e interdisciplinar que busquem a superação de problemas identificados no processo de ensinoaprendizagem; e) Incentivar escolas públicas de educação básica, mobilizando seus professores como conformadores dos futuros docentes e tornando as protagonistas nos processos de formação inicial para o magistério; e f) Contribuir para a articulação entre teoria e prática necessárias à formação dos docentes, elevando a qualidade das ações acadêmicas nos cursos de licenciatura" (Brasil, 2019, p. 1).

Partindo dessas premissas, este estudo teve como problemática responder "Em que medida o PIBID, Subprojeto de Biologia, cumpriu com o seu papel de Política Pública Educacional no ensino remoto no contexto da pandemia da Covid-19 no Colégio Estadual Newton Ferreira da Costa?”.

\section{Socialização profissional e trabalho colaborativo entre teoria e prática}

Desde sua formulação, o Programa Institucional de Bolsas de Iniciação à Docência (PIBID) vem se consolidando como uma das políticas públicas de formação mais bem sucedidas dos últimos tempos, Felício, Gomes e Allain (2015, p. 342) afirmam que o PIBID tem proporcionado sobretudo à Universidade, uma nova forma de conceber o processo de formação de professores de forma integradora em que ultrapassa os limites de seus muros para considerar a complexidade do cotidiano da escola pública como um "espaço" formador respeitando as objetividades e subjetividades e tida como um espaço que tem com o objetivo de formar e desenvolver cada indivíduo em seus aspectos cultural, social e cognitivo.

Nesse contexto, o Pibid, em função de sua dimensão integradora na profissão docente, além de ter sido decisivo na inserção do ambiente escolar com o protagonismo da docência também reverbera sobre a (re)construção da identidade docente

\footnotetext{
${ }^{1}$ Segundo Portal do MEC. Disponível em: http://portal.mec.gov.br/pibid
} 
para licenciandos, professores e educadores. Além disso, traz um sentido mais coerente para a teoria, pois reforça a importância da sua integração à prática, reforçando a complementaridade teoria-prática (Freire, 1970), visto que a teoria e prática se enriquecem mutuamente e, no caso da docência, uma não subsiste sem a outra.

Nesse bojo também se pode perceber a ideia de que a aprendizagem docente se dá ao longo da vida, pois, na verdade começa quando os professores ingressam no sistema educativo como alunos e continua até que dele saiam como docentes, por aposentadoria ou opção pessoal. Essa característica da aprendizagem docente leva ao uso da expressão desenvolvimento profissional de professores que substitui a palavra formação, por dar a ideia de um continuum.

A proposta de integração pelo PIBID na formação do(a) professor(a) deve ser compreendida em suas diversas facetas como um processo contínuo em que se baseia em diálogos permanentes com a realidade e nos diversos contextos em que se insere a escola. Além disso, no exercício de lidar com a inconstância dos desafios cotidianos da escola, aprende-se a planejar considerando contextos reais, estudantes reais e aprende-se a preparar materiais didáticos específicos para determinados estudantes, levando em conta seus interesses e necessidades. Há a possibilidade, por outra feita, de se compreender as bases e propósitos dos documentos oficiais, ao mesmo tempo em que se ousa experimentar, vivenciar e inovar no exercício da docência. Com isso, potencialmente, cresce o comprometimento dos participantes do PIBID que trabalham com o propósito comum de desenvolver abordagens e estratégias que motivem e envolvam o estudante da escola pública no processo de apropriação e construção do conhecimento científico.

Dessa forma, a atividade docente requer estratégias, ferramentas e habilidades que se tecem, de maneira particular, no contexto da vida e da formação acadêmica. A profissão docente instiga uma responsabilidade ao conectar-se ao aprendizado e à educação dos indivíduos, nos diálogos geracionais e projetos de futuro, nos quais é preciso possibilitar aprendizados que vão além da intervenção das disciplinas científicas, mas que abordem práticas sociais em sua concretude visando a humanização e a transformação social a partir da educação.

Sendo assim, as dimensões que se estabelecem na formação inicial dos docentes perpassam aspectos das estruturas curriculares e formativas, em especial a práxis, considerando o/a ser humano como sujeito histórico que se transforma conforme o mundo se modifica. Considerando Vázquez (1977), a práxis se configura na articulação entre pensamento e ação, passando a ser vista como uma relação indissociável entre teoria e prática, no sentido de que a teoria deva moldar a ação, desde que seja consciente, crítica e transformadora.

Partindo dessas premissas da indissociabilidade entre teoria e prática na formação docente e na práxis pedagógica, observa-se diversos teóricos que defendem está no âmbito da política educacional tais como: Nóvoa (1992; 2009), Franco (2006), Pimenta (2012), Gatti et al. (2019). Franco (2006). Estes destacam que as instituições de ensino superior devem considerar com maior intensidade a inserção do/a discente em formação no seu campo de trabalho, ou seja, a escola. Partindo dessa inserção, o/a discente como investigador/pesquisador/a poderá vislumbrar perspectivas e refletir sobre a realidade escolar e o trabalho docente. Esta articulação apresenta-se como essencial para uma formação com base na realidade social que se configura significativamente para a profissão docente (Brandt \& Hobold, 2019).

Nóvoa (1992) destaca que a inserção na escola, no lócus profissional, permite encontrar subsídios que colaboram essencialmente no processo de formação, nas reflexões sobre a profissão e na ampliação de seus saberes. Tardif (2012) corrobora e destaca que os anos iniciais de trabalho do/a professor/a são de fundamental importância e que nesse período são desenvolvidas competências e a prática docente.

Nesse ínterim a inserção de licenciandos através do PIBID no cerne da escola possibilita que estes vivenciem na inserção do exercício de docência permitindo um processo de reflexão na/sobre/para a prática, a fim de que se possa aprimorála, tendo como objetivo principal a aprendizagem do/a aluno/a. Conforme Tardif (2007): 
[...] a prática pode ser vista como um processo de aprendizagem por meio do qual os professores retraduzem sua formação e a adaptam à profissão, eliminando o que thes parece inutilmente abstrato ou sem relação com a realidade vivida e conservando o que pode servir-lhes de uma maneira ou de outra (Tardif, 2007, p. 53).

Portanto, a escola torna-se protagonista nos processos de formação do/as licenciado/as e os professores supervisores na escola dos participantes tornam-se co-formadores de futuros professores através da articulação entre ensino, pesquisa e extensão, que envolve a socialização profissional entre a escola e a universidade, no intuito de possibilitar reflexões sobre a melhoria no processo de ensino e aprendizagem tanto na Educação Básica, quando na Universidade.

Freitas (2002) define a socialização profissional como o mecanismo de inserção do/a futuro docente com seu lócus de atuação na qual se constitui de um espaço diverso entre as formas de "aprendizagem dos valores, crenças e formas de concepção do mundo, próprios de uma determinada cultura ocupacional” (Freitas, 2002, p. 156).

Cabe ressaltar, que muitas vezes as ideias que são construídas na academia através do discurso sobre a escola, são baseadas apenas na teoria, contudo, inúmeros desses discursos e ideias são desconstruídos ao entrarem em contato com a realidade escolar. Nesse processo, o novo docente chega à escola com seus ideais e entra em choque com uma dicotomia entre teoria e prática, cuja distinção ainda é recorrente em algumas realidades tanto da Educação Básica como na Educação Superior.

Dessa forma, percebe-se a importância do PIBID para desmistificar as narrativas que concentram em sua maioria nas hipóteses e enfoques teóricos e também para minimizar os discursos que distanciam a teoria e a prática através da socialização profissional em sua vivência no íntimo da escola, sendo este um espaço de formação fluída e constante, visto que a formação docente não se finda na formação inicial.

Nesse sentido, Flores (2010) sugere que a socialização profissional antecipatória, ou seja, durante a graduação, ameniza o choque causado no momento de incursão do novo docente, a qual carrega com si inúmeros paradigmas, crenças e teorias implícitas, e ainda, busca no próprio contexto educacional o caminho para desenvolver a prática docente. (Formosinho, 2009). Dessa forma a socialização escolar iniciada com o PIBID reforça a importância do trabalho colaborativo e reflexivo elencando as dificuldades a serem superadas entre a teoria e prática e também as potencialidades para a ressignificação do trabalho docente.

Dessa forma, o trabalho colaborativo proporcionado pela socialização profissional dos/as licenciandos/as e professores receptores se solidifica e constitui-se por pessoas que compartilham decisões, ou ações conjuntas e são responsáveis pela eficácia e qualidade de suas ações na práxis pedagógica, sendo então promotores de novos conhecimentos num processo que se dá pela troca de experiências e na construção de novas metodologias de ensino aprendizagem a partir da cooperação e da dialogicidade fortalecendo o trabalho cooperativo nos espaços escolares.

Diante das inúmeras dificuldades encontradas na Educação Básica, Nóvoa (2011) destaca a importância do trabalho colaborativo como um dos meios que podem proporcionar aos docentes oportunidades de aprendizagens e de trabalho com qualidade na compreensão dos significados e até mesmo a ressignificação da prática docente a partir da troca de experiências.

Nesta direção, Tardif (2007) aponta que um/a professor/a

não é somente alguém que aplica conhecimentos produzidos por outros, não é somente um agente determinado por mecanismos sociais: é um ator no sentido forte do termo, isto é, um sujeito que assume sua prática a partir dos significados que ele mesmo lhe dá, um sujeito que possui conhecimentos e um saber-fazer provenientes de sua própria atividade e a partir dos quais ele a estrutura e a orienta (Tardif, 2007, p. 230).

Dessa maneira, através da sua atividade como docente, e também pela troca de experiências, é que os profissionais começam a reconhecer o que sabem e refletem sobre sua prática, de modo a ressignificar a sua maneira de pensar e agir na docência, proporcionando novas possibilidades de estarem resolvendo seus dilemas tanto na reflexão e ação individual, quanto no coletivo. Dessarte, 
o saber não é uma coisa que flutua no espaço: o saber dos professores é o saber deles e está relacionado com a pessoa e a identidade deles, com a sua experiência de vida e com a sua história profissional, com as suas relações com os alunos em sala de aula e com os outros atores na escola, etc. (Tardif, 2002, p.11).

Assim, o trabalho colaborativo proporciona a solidariedade, a troca de experiências e de valores, saberes que não podem ser desenvolvidos individualmente, ou seja, a conjunção entre o saber e o trabalho colaborativo no sentido de ressignificar ou provocar as reflexões para contribuir com a melhoria da qualidade do ensino se faz no entendimento que não podemos pensar pelo outro, para o outro e sem o outro. A educação é feita com o outro que também é sujeito, que tem sua identidade e individualidade a serem respeitadas no processo de questionamento, dos comportamentos e da realidade (Marques \& Xavier, 2018; Marques \& Xavier, 2021).

Nóvoa (2009) destaca a importância dos processos de aprendizagem compartilhada e da cultura colaborativa na construção do conhecimento profissional dos/as professores. Segundo o autor (ibidem), entender a escola como lugar da formação dos professores implica considerá-la como espaço da análise partilhada das práticas e de reflexão sobre o trabalho docente. Ele lembra ainda que o exercício desse diálogo envolve regras e procedimentos que precisam ser aprendidos e exercitados nos cursos de formação. Assim, o exercício da reflexão coletiva sobre as atividades, favorecido no PIBID, aponta perspectivas de formação de professores capazes de discutir e refletir sobre suas práticas, agindo como atores coletivos na construção do conhecimento profissional docente (Nóvoa, 2009).

\section{Metodologia}

A pesquisa de abordagem qualitativa foi aplicada na perspectiva exploratória e descritiva como forma de compreender uma realidade que se constituiu de forma muito rápida e que reconfigurou diferentes estruturas sociais e instituições, dentre elas, as escolas, em especial no que se refere aos processos de ensino e de aprendizagem.

Ludke e André (2015) asseveram que o papel do pesquisador na abordagem qualitativa é de estar atento à multiplicidade de dimensões de uma determinada situação ou problema e após a análise dos dados, ele lança possibilidades de explicação da realidade, tentando encontrar princípios subjacentes ao fenômeno estudado e situar as suas descobertas num contexto mais amplo; trata-se de um esforço de construção ou estruturação de um quadro teórico, dentro do qual o fenômeno possa ser interpretado e compreendido.

Recorremos às postulações de Bogdan e Biklen (1994) quanto ao fato de que para a realização de uma pesquisa qualitativa exploratória devem ser considerados elementos como: a) a fonte de dados é o ambiente natural para esta abordagem de investigação; b) a condição descritiva da pesquisa; c) os pesquisadores focam os resultados a partir do processo e não somente a partir dos resultados encontrados; d) os dados são analisados de forma indutiva e; e) os pesquisadores precisam considerar a diversidade de opiniões sobre o fenômeno investigado, seja quanto a aspectos positivos ou negativos associados ao objeto de estudo em análise.

A presente pesquisa foi realizada com os participantes do Programa Institucional de Bolsas de Iniciação à Docência (PIBID) subprojeto de Biologia com acadêmicos do Curso de Licenciatura em Ciências Biológicas pela Universidade Federal do Paraná - Curitiba/PR que formaram a equipe do Colégio Estadual Newton Ferreira da Costa.

Salienta-se que devido a pandemia do Covid-19 e a necessidade de isolamento social (consequentemente suspensão das atividades presenciais escolares por tempo indeterminado) utilizou-se como instrumento de coleta de dados a aplicação de um questionário online que foi enviado via WhatsApp. O questionário contou com 1 pergunta discursiva e 5 perguntas de múltipla escolha, estruturadas na Escala Likert. 
Utilizou-se o questionário via Formulários Google criado para alcançar o objetivo desta pesquisa, ou seja, analisar as contribuições do Programa Institucional de Bolsas de Iniciação à Docência - PIBID, na formação inicial dos bolsistas de Licenciatura em Biologia no Colégio Estadual Newton Ferreira da Costa, na cidade de Curitiba - PR.

A Escala Likert é defendida por Reis (1997), Garland (1991); Oliveira (2001) e Aguiar et al (2011), entre outros, para subsidiar a análise de dados a partir da percepção dos entrevistados.

Segundo Aguiar et al., (2011) a Escala Likert

são escalas de autorrelato mais difundidas, consistindo em uma série de perguntas formuladas sobre o pesquisado, onde os respondentes escolhem uma dentre várias opções, normalmente cinco, sendo elas nomeadas como exemplo: concordo muito, concordo parcialmente, neutro/indiferente, discordo parcialmente e discordo muito. Para ser considerada uma escala Likert, no entanto, é preciso que cada item seja apresentado sob forma de uma pergunta, com cada gradação como uma resposta possível, além de cada gradação se mostrar numa ordem descendente, onde o primeiro item indica o maior grau de concordância, o último o maior grau de discordância e o item do meio neutro, sendo bivalentes e simétricos (Aguiar et al., 2011, p. 2).

As escalas de Likert dizem respeito a uma série de afirmações relacionadas com o objeto pesquisado, utilizando para isso mais de um tipo de escala, entre as descritas anteriormente. Ou seja, "[...] os respondentes não apenas respondem se concordam ou não com as afirmações, mas também informam qual seu grau de concordância ou discordância." (Oliveira, 2001, p. 19). Uma vantagem da escala de Likert é a possibilidade de identificar a direção da atitude do respondente em relação a cada afirmação, sendo ela positiva ou negativa e poder utilizá-las para repensar os pontos que podem ser melhorados para contribuir com o objeto da investigação.

As questões do questionário buscam identificar a concepção dos entrevistados a partir da problemática, "Em que medida o PIBID, Subprojeto de Biologia, cumpriu com o seu papel de Política Pública Educacional no ensino remoto no contexto da pandemia da Covid-19 no Colégio Estadual Newton Ferreira da Costa?". A preferência pelo método se deu porque, "entre as principais vantagens dos levantamentos, estão: conhecimento direto da realidade; economia e rapidez" (Prodanov, p. 58, 2013). Os entrevistados a partir da aplicação do questionário foram mantidos anônimos e os mesmos foram identificados durante o texto como "Entrevistado P" onde "P01; P02; P03 etc." está relacionado com a quantidade de pessoas entrevistadas. Após a coleta de dados, os mesmos foram analisados, sintetizados e discutidos conforme veremos.

\section{Resultados e Discussão}

Essa pesquisa contou com a participação de 10 licenciandos em Ciências Biológicas participantes do PIBID, participantes na equipe do Colégio Estadual Newton Ferreira da Costa, sendo 8 bolsistas e dois voluntários. O questionário foi aplicado em Julho de 2021, após um ano de participação dos (as) pibidianos (as). É importante ressaltar que o desenvolvimento e execução do Projeto Institucional de Bolsas de Iniciação à Docência no Colégio Newton Ferreira da Costa 2020/2021 se deu no formato remoto visto as exigências e deliberações sobre o processo de virtualização de emergência com o avanço da Covid19 e em cumprimento das exigências de distanciamento e isolamento social como forma de barrar e de minimizar a transmissão do coronavírus (Marques, 2021). Dessa forma, a aplicabilidade e execução das atividades do programa interfere também sobre o aproveitamento de cada participante e sobre o curto período de tempo para que todos pudessem replanejar e se adaptar as novas condições impostas pelo ensino remoto. Nesse período, podemos trazer a reflexão em que Contreras (2002, p. 33) afirma que "o trabalho docente sofreu uma subtração progressiva de uma série de qualidades que conduziram os professores à perda de controle e sentido sobreo próprio trabalho, ou seja, a perda de autonomia", por outro, lado pode-se observar que a educação se move em meios aos desafios da pós-modernidade e que os(as) docentes, licenciandos(as), 
estudantes ademais se organizaram celeremente no sentido de oportunizar uma educação de qualidade que atenda os dilemas e desafios aos quais interferem sobre as atividades humanas.

Os resultados foram organizados e transcritos para uma análise quanti-qualitativa das respostas das questões do questionário. Por ser, uma pesquisa exploratória e descritiva, o conteúdo não foi analisado a partir de categorias pré ou pós estabelecidas, buscando assim, explicitar os aspectos mais gerais das percepções dos participantes e a sua importância a partir das discussões geradas à luz dos autores que fundamentam a pesquisa.

A primeira questão: "Em que aspectos o PIBID como Política Pública Educacional contribui para sua formação como Professor da Educação Básica?" nesta, dos aspectos positivos, no geral de caráter, podemos destacar a fala dos participantes:

$\mathrm{P} 02$ "Ter o primeiro contato com a docência, ter a experiência de como fazer um planejamento e aplicá-lo; aprender a ter vínculo emocional com os alunos e ainda ver a importância de trazer atividades mais dinâmicas nas aulas". P03 "Vivenciar na graduação a realidade da educação pública, aprendizado prático de metodologias de ensino e possibilidade de participar de discussões e debates sobre diferentes assuntos relevantes na sociedade.

P04 "O Pibid permite um contato mais direto com os alunos do ensino médio; incentiva o desenvolvimento de estratégias para captar a atenção dos alunos; colabora no aprendizado de métodos avaliativos e planos de aula; permite experimentar o papel de docente ainda durante a graduação".

P07 "[...] O projeto permite que, durante a graduação, a partir de discussões entre os pibidianos, termos uma noção das diferentes realidades dos colégios e assim podemos refletir sobre a educação pública. [...]Ao acompanharmos o professor supervisor podemos observar seu método de ensino e continuamente aprender até o momento de darmos a aula. Tendo esse acompanhamento, além de ter aconselhamento, o supervisor avalia os momentos que os alunos exerceram à docência, o que considero de extrema importância em nossa formação, pois cada ponto apresentado pelo professor, seja uma crítica positiva ou negativa, nos permite aprender para que possamos continuamente melhorar nossa prática docente."

P10 "Melhora a qualidade de produção das aulas; auxilia na nossa integração dentro das salas de aulas; ajuda a desenvolver autonomia e compromisso"

Pode se observar nas respostas dos discentes quando afirmam sobre a importância de se conhecer, experimentar e vivenciar à docência, tanto no exercício da docência, ao fazer o planejamento, utilizar e buscar novas metodologias, ter vínculo emocional, afetividade na integração com os alunos entre outros. Além disso, ter compromisso e autonomia são elementos intrínsecos a práxis pedagógica e são princípios fundamentados nos quatro Pilares educacionais para a educação em que tece as relações com as competências "aprender a conhecer; aprender a fazer; aprender a ser; aprender a conviver” (Delors, 2003).

Desta maneira, é possível entender a importância do programa para a formação inicial de professores na perspectiva de quem está se preparando para adentrar ao mundo da educação e está vai de acordo às necessidades pré-estabelecidas pelo Ministério da Educação $(2005$, p. 8) que é a "formação teórica ampla e consistente, visão contextualizada dos conteúdos de sua área de atuação, de forma a garantir segurança em seu trabalho".

Cabe ressaltar que a formação inicial e continuada,

não pode ser concebida como um meio de acumulação (de cursos, palestras, seminários, etc., de conhecimentos e técnicas), mas sim através de um trabalho de reflexividade crítica sobre as práticas e de (re)construção permanente de uma identidade pessoal e profissional, em interação mútua. E é nessa perspectiva que a renovação da formação continuada vem procurando caminhos novos de desenvolvimento (Candau, 1997, p. 64).

A participação dos/as licenciandos/as no PIBID se efetiva de forma positiva ao se analisar as suas respostas, pois os mesmos que afirmaram obter autoconfiança, amadurecimento e aprendizagem como profissional docente, auxílio e destaque no desenvolvimento de novas propostas metodológicas, planejamento, avaliação etc., estão comprometidos com a prática docente e com o aprimoramento dos seus conhecimentos. 
Corrêa e Batista (2013) ressaltam que ao adentrar no âmbito escolar, o acadêmico adquire autoconfiança e controle de si mesmo em momentos inesperados, alcançam também a postura em sala de aula, aprendem a avaliar o conhecimento dos alunos, e conseguem discernir quanto as dinâmicas de grupo e os variados ritmos de aprendizagem. O programa beneficia os bolsistas com a aquisição de uma maior determinação, responsabilidade e disciplina, participando da construção da identidade docente dos acadêmicos e também a fazerem uma autoavaliação quanto sujeitos que ensinam e aprendem através da educação.

Partindo desses elementos que retratam a importância do Programa Institucional de Bolsas de Iniciação à Docência (PIBID), buscou-se saber dos participantes um panorama sobre as suas percepções sobre alguns elementos gerais acerca do papel do PIBID como Política Educacional e também a sua importância para possibilitar a estes aprender a conhecer, socializar, fazer e ser quanto acadêmicos e futuros docentes.

Dessa forma, o primeiro elemento investigado a partir da Escala Likert se deu a partir da Questão "Você considera que o PIBID melhorou seu entendimento sobre o processo de ensino e aprendizagem?" foi dada numa escala de 1 a 5 onde se tem que 1- discordo totalmente; 2- discordo parcialmente; 3- indiferente, 4- concordo parcialmente e 5- concordo totalmente. Nos resultados, obteve-se que $60 \%$ afirmam que o PIBID melhorou o entendimento sobre o processo de ensino e aprendizagem com a escolha da resposta "concordo totalmente" e ainda 40\% dos participantes declaram que "concorda parcialmente". Neste sentido, pode-se perceber a importância da vivência na realidade escolar mesmo no ensino remoto pois esta experiência permite aos licenciandos testar a teoria na prática. Por outro lado, não há receita pronta para que o professor tenha sucesso no processo ensino-aprendizagem e, portanto, também não deve haver padronização de ações para resolver essas dificuldades. É importante ressaltar que o ensino remoto também interfere a compreensão e análise sobre o processo de ensino e aprendizagem, visto que o processo educativo via ensino remoto interfere sobre fatores que são importantes no ensino presencial, tais como afetividade, os momentos de questionamentos e debates, que no ensino remoto acaba sendo reduzido e muitas vezes inexistentes.

Nesse sentido, pode-se afirmar que a prática docente e a forma de trabalhar com os estudantes devem ser modificadas e autoavaliadas constantemente devido ao fato de que cada aluno age e aprende de maneira diferente (Natel et al., 2013). A experiência adquirida durante a participação do PIBID permite ao licenciando rever seus conceitos em relação ao processo ensino-aprendizagem ao compreender outros fatores que são estabelecidos na relação entre professor e estudantes tais como a "existência de material na estrutura cognitiva do sujeito, a predisposição para aprender, e o esforço decidido para aprender, no sentido cognitivo e afetivo" (Moreira, 2003, p. 13), a qual o professor deve ter um olhar crítico, reflexivo e buscar resgatar e reformular o modo de ensino e as metodologias para promover uma educação mais humaniza e que se efetive na transformação social.

Nesse seguimento, buscou-se entender a percepção dos licenciandos sobre a influência do Programa Institucional de Bolsas de Iniciação à Docência no Colégio Estadual Newton Ferreira da Costa para a melhoria na qualidade do ensino. Estes foram inquiridos com a questão "A qualidade do ensino na escola em que você atua é afetada pelas ações do PIBID?" foi dada numa escala de 1 a 5 onde se tem que 1- discordo totalmente; 2- discordo parcialmente; 3 - indiferente, 4- concordo parcialmente e 5- concordo totalmente; na qual se obteve que 50\% responderam "concordo totalmente", 30\% "concordo parcialmente" e $20 \%$ "indiferente". Observa-se que o PIBID na sua premissa proporciona mudanças significativas e positivas no colégio receptor, no engajamento, na motivação para ressignificar as metodologias de ensino, na participação dos estudantes etc. Os vieses que se referem as variáveis entre os $30 \%$ "concordo parcialmente e $20 \%$ "indiferente" pode ser justificada ou entendida pelo fato da ausência do contato mais afetivo no espaço físico da escola, que infere muitas vezes sobre a motivação, autonomia e sobre a capacidade de "desenvolver a habilidade de ter uma aprendizagem autônoma" (Ferreira; Silva, 2009, p. 4) no contexto de isolamento social. Nesse ínterim, a pandemia do Covid-19 nos remete à reflexão do quanto "é importante a relação interpessoal principalmente na relação entre professores(as) e alunos(as), pois a falta de contato físico, por muitos, 
pode ser considerada um impedimento para expressar sentimentos e uma comunicação assertiva" (Marques, 2021, p. 10) e que tenha resultado na aprendizagem e também na qualidade do trabalho pedagógico.

Pode-se destacar o efeito do trabalho colaborativo que funciona como um precursor de novos conhecimentos, pela troca de experiências entre os docentes e com os licenciandos, proporcionando aos envolvidos oportunidades de aprendizagens e de trabalho com qualidade (Nóvoa, 2011; Sá \& Garritz, 2015). Nono \& Mizukami (2001) salientam a importância do compartilhamento de experiências entre professores, explicando que pode favorecer o desenvolvimento da destreza na análise crítica, na resolução de problemas e na tomada de decisões.

Ao indagar aos licenciandos "Em que frequência o PIBID te ajudou ou ajuda nas questões de planejamento, métodos avaliativos e comunicação com os alunos?", foi dada numa escola d 1 a 5, onde 1- nunca; 2- raramente; 3- às vezes; 4- frequentemente e 5- muito frequentemente; se obteve que $60 \%$ dos licenciandos afirmam que "muito frequentemente", $20 \%$ "frequentemente" e ainda 20\% "ás vezes". Observa-se a importância do Programa para o exercício da práxis docente, visto que o planejamento para as ações do fazer pedagógico indiscutivelmente, organiza e sistematiza o trabalho pedagógico, evitando a improvisação. Assim, na perspectiva da previsão e da intencionalidade, evocamos Padilha (2001) que corrobora ao afirmar que realizar planos, planejamentos, bem como métodos avaliativos,

significa exercer uma atividade engajada, intencional, científica, de caráter político e ideológico e isento de neutralidade. Planejar, em sentido amplo, é um processo que visa dar respostas a um problema, através do estabelecimento de fins e meios que apontem para a sua superação, para atingir objetivos antes previstos, pensando e prevendo necessariamente o futuro, mas sem desconsiderar as condições do presente e as experiências do passado, levando-se em conta os contextos e os pressupostos filosófico, cultural, econômico e político de quem planeja e de com quem se planeja (Padilha, 2001, p. 63).

Ao destacar, os $20 \%$ que afirmam que "às vezes" a participação no PIBID ajuda nas questões de planejamento, métodos avaliativos e comunicação com os alunos, mostra-se um bom indicador para buscar a reflexão sistemática e questionadora frente ao papel de cada um diante da importância de se debater e elaborar o planejamento, contudo, não se pode pensar o planejamento escolar sem considerar também as interferências externas, como as questões emocionais, culturais, sociais, entre outros fatores que podem interferir sobre a execução deste no processo de ensino e aprendizagem. Temos que o espaço escolar é vívido e repleto de situações que influência o fazer pedagógico e como integrantes desse contexto devemos estar prontos para compreender os elementos entre o planejamento ideal e o real para que possamos avançar quanto as questões que envolvem a dinâmica do espaço educativo, visto que por meio da educação pode se alcançar a transformação do sujeito e da sociedade, dessa forma o planejamento, o currículo e a avaliação devem estar interligados de maneira que um seja complemento e ao mesmo tempo extensão um do outro com o objetivo de buscar a humanização e transformação social.

Na aplicabilidade do PIBID no Colégio Newton Ferreira da Costa que em função da pandemia da Covid-19 estava em ensino remoto. Buscou-se entender na percepção dos pibidianos se "A utilização de recursos metodológicos alternativos com a utilização de tecnologias nas aulas síncronas contribui para melhorar o ensino remoto?”. Foi dada numa escala onde 1 não é importante; 2 - às vezes importante; 3 - moderado; 4 -importante e 5 - muito importante, onde $80 \%$ afirmam ser “muito importante" e 20\% “importante". Dessa forma, é inegável a importância de recursos metodológicos com a utilização das tecnologias para favorecer o processo de ensino e aprendizagem.

Nesse sentido, Ponte (2000) reafirma que a utilização das tecnologias "poderão ajudar na aprendizagem de muitos conteúdos", além de possibilitar "a criação de espaços de interação e comunicação, pelas possibilidades alternativas que fornecem de expressão criativa, de realização de projetos e de reflexão crítica" (Ponte, 2000, p.14). 
Nesse sentido, Menezes (2006) observa a importância e a necessidade de integração das tecnologias digitais ao contexto escolar, a educação apresenta a tendência de abandonar a preparação apenas técnica dos alunos (prática instrucionista), voltando-se a formação de alunos com valores, criatividade e autonomia (abordagem construtivista), destacando que os avanços tecnológicos e seu impacto no desenvolvimento humano afetam o modo de ensinar e aprender o mundo, ocorrendo assim uma (re)significação das práticas educativas.

No processo de ensino e aprendizagem, tanto os alunos quanto os docentes passam por várias etapas: relacionam novos conhecimentos com os que já sabem, elaboram e testam hipóteses, pensam onde aplicar o que estão aprendendo, expressam-se por meio de várias linguagens, aprendem novos métodos e conceitos, aprendem a ser críticos, analíticos etc. Dessa forma, a incorporação de recursos tecnológicos em processos educacionais pode trazer benefícios a esses processos e acaba gerando neles interferências estruturais. No entanto, é preciso romper com a visão conservadora, observando que mais importante do que apontar quais os seus problemas é verificar quais as suas virtudes.

Ao compreender a percepção dos licenciandos sobre a imersão destes diante dos desafios da profissão docente e os fatores que contribuem com o processo de ensino e aprendizagem. Buscou-se a partir da questão "A sua participação no PIBID favorece a experiência de permanecer no curso de Licenciatura em Ciências Biológicas?" compreender a potencialidade do Programa Institucional de Bolsas de Iniciação à Docência (PIBID) para a permanência e formação inicial destes. Malaquias et al., (2019) afirma que um dos objetivos do PIBID é contribuir para a permanência dos licenciados no magistério. Dessa forma é se suma importância visto que no estudo de Azevedo (2019) é apresentado em sua complexidade um alto índice de desistência nos cursos de licenciatura envolvendo questões políticas, econômicas, sociais e administrativas, mas também aspectos pedagógicos, psicológicos etc. Foi dada numa escala de 1 a 5, onde 1 - quase sempre falso; 2 - geralmente falso; 3 - às vezes é verdade; 4 - geralmente verdade; 5 - quase sempre verdade. Obteve-se que $40 \%$ afirmam ser "quase sempre verdade", $40 \%$ "geralmente verdade", $10 \%$ dizem ser "geralmente" falso e $10 \%$ "quase sempre falso". Com esses dados temos um bom indicador sobre a importância do PIBID como fator decisório ou que contribui com a reflexão destes para a permanência e manutenção na profissão docente. Isso vai ao encontro aos estudos de Deimling e Reali (2017) que também estudaram a importância do PIBID no desejo dos bolsistas em seguir carreira de docente após o término do curso de licenciatura e que o programa os influenciou positivamente nessa escolha. Por outro, lado pode-se perceber sobre os dados em que "10\% dizem ser geralmente falso" e 10\% "quase sempre falso" deve ser investigado a fim de apresentar os significados a partir desses dados. Contudo, conforme Caldeira (2013) os desafios diante do contexto do ensino remoto podem causar prejuízos tanto na vida dos docentes, estudantes e os (as) pibidianos(as), visto que estes "tiveram que reorganizar a maneira como ensina(va)m" (Coelho, 2012, p. 89).

O momento pandêmico vivido eleva a condição da formação inicial e continuada de professores e também a um status ainda maior, fazendo-se extremamente necessária em face do ensino remoto. Marques et al., (2017) afirmam que o diálogo favorece o espaço de formação, de troca de experiências, de desabafo, muda caminhos, forja opiniões, razão etc. A troca entre os docentes e licenciandos participantes do Programa Institucional de Bolsas de Iniciação à Docência - PIBID sobre a organização do trabalho docente quanto aos recursos didáticos, planejamento e acesso aos conteúdos entre outros podem ser um facilitador para que juntos façam reflexões sobre as práticas vividas no ambiente virtual para que se possa qualificar e redirecionar o trabalho a todo o momento, pois a condição de distanciamento coloca-nos em uma sensação de contínua instabilidade ao que é planejado e o que efetivamente acontece" (Canal \& Rozek, 2021, p. 2678). Nesse sentido, o ensino remoto deve provocar reflexões no sentido de ressignificar o processo de ensino e aprendizagem diante dos problemas e desafios da pós-modernidade e em pleno dialogo e trabalho colaborativo possa-se junto trazer benefícios ao processo de ensino e aprendizagem minimizando as frustações, medos e equívocos que surgem ao diante "do trabalho que se constitui como uma estratégia tanto econômica quanto política do capital" (Souza, 2017, p.182). 


\section{Considerações Finais}

Diante dos resultados e discussões aqui apresentados é possível constatar que a importância do projeto para a escolha profissional dos acadêmicos é representativa, e na maioria positiva uma vez que o PIBID funciona como ponte entre universidade-teoria, com escola-prática. E essa ponte permite a socialização e integração do futuro docente no sentido de ter uma visão mais realista e menos idealista do contexto escolar como docente.

Pode-se perceber que a participação no Programa Institucional de Bolsas de Iniciação à Docência - PIBID contribui significativamente na melhoria do entendimento sobre o processo de ensino e aprendizagem, aumentando o grau de interesse em seguir a carreira docente e em permanecer no curso. Além disto, os licenciandos afirmam que as ações do PIBID, afetaram a qualidade do ensino na escola em que atuam. Partindo dessas constatações pode-se perceber a importância deste programa para a formação inicial destes discentes, tanto quanto para as escolas da rede pública e seus alunos.

Durante todo este artigo, procurou-se explicitar a importância do PIBID na formação docente ficando nítido que a maioria dos licenciandos pesquisados possuem essa percepção. O/A “pibidiano/a” possui experiências únicas que raramente outros estágios são capazes de proporcionar, pois trabalha com toda estrutura do trabalho pedagógico, além dos recursos materiais e com professores selecionados que acreditam no projeto. Os questionários demonstraram o que já se esperava e ratificaram que o programa de iniciação à docência cumpre com sua função de incentivar os licenciandos a seguir a carreira docente, valorização da função de professor, pesquisa de novas e eficientes metodologias de ensino, assim como promover a melhoria da qualidade da educação.

Ao final desta pesquisa, concorda-se com o enunciado de Weber et al., (2013), quando diz que o PIBID proporciona muito mais que um contato com o ambiente escolar e com o cotidiano da profissão, mas que pode influenciar na mudança das concepções dos alunos sobre a profissão docente, tornando-os profissionais críticos e reflexivos, que conhecem a realidade escolar e seus desafios, além de demonstrar e reconhecer a importância do professor para a sociedade.

Outro ponto importante é que o projeto não engrandece apenas docentes e licenciandos, mas principalmente alunos de escolas públicas, em que todos estão no ensino remoto no contexto da pandemia pela Covid-19. Isto é, o impacto nos alunos das escolas de educação básica, na qual os desafios são inúmeros diante do processo de virtualização de emergência em que muitos estão totalmente isolados e as aulas acabam sendo o maior meio de interação com as pessoas, revelou-se como positivo visto que o nível de interação, afetividade e participação dos estudantes foi crescendo significamente ao longo da execução do projeto.

Nesse sentido as experiências individuais e coletivas e o impacto pedagógico sobre estes, demonstram a essencialidade do PIBID para a formação de professores e com isso, a esperança de profissionais mais reflexivos, críticos e que contribuirão melhor para educação de seu país. Por não ser tão valorizado a figura do professor no nosso país, todos os incentivos à formação docente é bem-vinda e se deve valorizar. O PIBID é uma realidade essencial e cada vez mais necessária ao nosso sistema educacional e deve ser ampliado para atingir mais licenciandos.

\section{Agradecimentos}

À CAPES, pelo financiamento do programa PIBID/UFPR-PR.

\section{Referências}

Aguiar, B. et al. (2011). "Uso da Escala de Diferencial Semântico na Análise de Jogos". Em: Anais do X Simpósio Brasileiro de Games e Entretenimento Digital, 07-09 de novembro de 2011.

Azevedo, A. R. (2019). “A evasão nos cursos de licenciatura: onde está o desafio?”. Cadernos de Estudos e Pesquisas em Políticas Educacionais. Pesquisa em Educação e Transformação. 13, 1-34. 
Bogdan, R. C. \& Biklen, S. K. (1994). "Investigação qualitativa em educação". Tradução Maria João Alvarez, Sara Bahia dos Santos e Telmo Mourinho Baptista. Porto Editora.

Brandt, A. G. \& Hobold, M. S. (2019). “A Prática como componente curricular na disciplina pesquisa e processos educativos do curso de pedagogia: Um diferencial na relação entre pesquisa, teoria e prática". Educação \& Formação. 4(2), 142-160.

Caldeira, J. S. (2013). "Relação Professor-Aluno: uma reflexão sobre a importância da afetividade no processo de ensino aprendizagem”. Anais do XI Congresso Nacional de Educação (XI EDUCERE) / II Seminário Internacional de Representações Sociais, Subjetividade e Educação (II SIRSSE) / do IV Seminário Internacional sobre Profissionalização Docente (IV SIPD). Curitiba: PUC-PR.

CanaL, S. \& Rozek, M. (2021). “Tempos de pandemia: reflexões sobre a escola, os sujeitos e suas diferentes necessidades”. Brazilian Journal of Development, Curitiba. 7(1), 2674-2683

Candau, V. M. (Org.). (1997). “Magistério: construção e cotidiano”. Vozes.

Coelho, P. M. F. (2012). "Os nativos digitais e as novas competências tecnológicas". Texto livre linguagem e tecnologia. 5, 88-95.

Contreras, J. (2002). “Autonomia de professores”. Cortez.

Deimling, N. N. M \& Reali, A. M. M. R. (2017). "O programa institucional de bolsa de iniciação à docência, as escolhas profissionais e as condições de trabalho docente". Educ. rev., 33, e143999.

Delors, J. (2003). “Educação: um tesouro a descobrir”. (2a ed.), MEC/UNESCO.

Felício, H. M. S., Gomes, C. \& Allain L. R. (2014). "O Pibid na ótica dos licenciandos: possibilidades e limites no desenvolvimento do programa". Educação, Santa Maria. 39, (2), 339-352.

Ferreira, R. B. A. S.\& Silva, I. M. M. (2009). "Didática no contexto da educação a distância: quais os desafios?” Revista Brasileira de Aprendizagem Aberta e a Distância. vol. 8 .

Formosinho, J. O (org.). (2009). "Formação de professores: Aprendizagem profissional e ação docente”. Porto Editora.

Flores, M. A. (2010). “Algumas Reflexões em torno da formação inicial de professores”. Educação. 33(3)182 - 188.

Franco, M. A. S. (2006). "Para um currículo de formação de pedagogos: indicativos". In: Pimenta, S. G. (Org.) Pedagogia e pedagogos: caminhos e perspectivas. Cortez, 99-128.

Freire, P. (1970). “Pedagogia do Oprimido". Paz e Terra.

Freitas, M. N. V. (2002). “Organização Escolar e Socialização Profissional de Professores Iniciantes”. Cadernos de Pesquisa, n. 115.

Garland, R. (1991). “The mid-point on a rating scale: is it desirable?” Marketing Bulletin, [S.1.], .2 .66-70.

Gatti, B. et al. (2019). "Professores do Brasil: Novos Cenários de Formação”. UNESCO. 351p.

Gatti, B. A. (2014). “A formação inicial de professores para a educação básica: as licenciaturas”. Revista USP, (100), 33-46.

Ludke, M; André, Marli, E. D. A. (2015). "Pesquisa em educação: abordagens qualitativas". E.P.U.

Malaquias, D. S. L., \& Cardoso, S. P. (2019). "Aspectos da formação docente e interlocuções com o programa de iniciação à docência”. Research, Society and Development, 8(5), e4485972.

Marques, R.; Fraguas, T., Torales, M. A. C. (2021). "Os professores frente ao trabalho remoto: a Covid-19 como determinante para uma "virtualização de emergência". Debates em Educação. 13. 1-22.

Marques, R., \& Xavier, C. R. (2021). "Assumptions for developing the critical sense through the teaching and learning process". International Journal on Social and Education Sciences (IJonSES), 3(1), 68-81.

Marques, R. (2021). “O professor em trabalho remoto no contexto da pandemia da Covid-19”. Boletim De Conjuntura (BOCA), 6(16), 06-14.

Marques, R.; Fraguas, T. (2020). “A ressignificação da educação: virtualização de emergência no contexto de pandemia da Covid-19”. Brazilian Journal of Development. 6, 86159-86174,

Marques, R., \& Xavier, C. R. (2018). Análise do Senso Crítico em uma Sequência Didática na Educação Ambiental. REMEA - Revista Eletrônica Do Mestrado Em Educação Ambiental, 35(1), 132-150.

Marques, R. et al. (2017). “Compostagem como ferramenta de aprendizagem para promover a educação ambiental no ensino de ciências”. Anais do $8^{\circ}$ Fórum Internacional de Resíduos Sólidos. Curitiba, 2017.

Menezes, E. C. P. (2006). Informática e Educação Inclusiva: Discutindo Limites e Possibilidades. Editora UFSM. 130p.

Moreira, M. A. (2006). “A teoria da aprendizagem significativa e sua implementação em sala de aula”. Editora Universidade de Brasília.

Natel, M. C., Tarcia, R. M. L., Sigulem, D. (2013). “A aprendizagem humana: cada pessoa com seu estilo". Revista Psicopedagogia. 30, 142- 148. 
Research, Society and Development, v. 10, n. 10, e118101018534, 2021

(CC BY 4.0) | ISSN 2525-3409 | DOI: http://dx.doi.org/10.33448/rsd-v10i10.18534

Nono, M. A.; Mizukami, M. G. N. (2001). “Aprendendo a ensinar: futuras professoras das séries iniciais do ensino fundamental e casos de ensino". In: Reunião anual da Anped, 24, Caxambu, 2001. Anais. Caxambu. 1-16.

Nóvoa, A. (1992). "Os professores e a sua formação”. Dom Quixote.158p.

Nóvoa, A. (2009). "Professores: imagens do futuro presente". Educa. 95p.

Nóvoa, A. (2011). “O Regresso dos Professores”. Editora Melo.

Oliveira, T. M. V. (2001). "Escalas de mensuração de atitude: Thrstone, Osgood, Stapel, Likert, Guttman, Alpert”. Revista Administração online, 2 (2), abr./jun.

Padilha, P. R. (2001). "Planejamento Dialógico: Como construir o projeto político pedagógico da escola". Ed. Cortez.

Pimenta, S. G. (2012). “Saberes pedagógicos e atividade docente”. (8a ed.), Cortez,304p.

Ponte, J. P. (2000). “Tecnologias de informação e comunicação na formação de professores: que desafios?”. Revista Ibero Americana. 24, setembro/dezembro.

Prodanov, C. C. \& Freitas, E. C. (2013). "Metodologia do trabalho científico: métodos e técnicas da pesquisa e do trabalho acadêmico". (2a ed.), Feevale.

Reis, E. (1997). “Estatística multivariada aplicada”. Edições Silabo.

Sá, L. P. \& Garritz, A. (2015). "Perspectiva de Estudantes de Química sobre Uma Proposta de Produção e Aplicação de Unidades Didáticas e o Impacto do PIBID na Formação Docente”. Química Nova na Escola. 37 (3). 187-196.

Souza, A. S. de, Nery, M. de S., Souza, S. A. N., \& Azevedo, D. P. de. (2020). "Formação inicial de professores: as lacunas presentes em seu percurso formativo e possíveis caminhos de superação". Cenas Educacionais, 3, e9488

Tardif, M. (2012). “Saberes docentes e formação profissional”. (13a ed.), 328p.

Tardif, M. (2007) "Saberes docentes e formação profissional”. (8a ed.), RJ. Vozes.

Vazquez, A. S. (1977). "Filosofia da práxis". Paz e Terra. 448p. 